\title{
Witnessing workplace bullying and employee well-being: A two-wave field study
}

DOI:

10.1037/ocp0000137

\section{Document Version}

Accepted author manuscript

Link to publication record in Manchester Research Explorer

\section{Citation for published version (APA):}

Sprigg, C. A., Niven, K., Dawson, J., Farley, S., \& Armitage, C. J. (2018). Witnessing workplace bullying and employee well-being: A two-wave field study. Journal of Occupational Health Psychology, 24(2), 286-296. https://doi.org/10.1037/ocp0000137

\section{Published in:}

Journal of Occupational Health Psychology

\section{Citing this paper}

Please note that where the full-text provided on Manchester Research Explorer is the Author Accepted Manuscript or Proof version this may differ from the final Published version. If citing, it is advised that you check and use the publisher's definitive version.

\section{General rights}

Copyright and moral rights for the publications made accessible in the Research Explorer are retained by the authors and/or other copyright owners and it is a condition of accessing publications that users recognise and abide by the legal requirements associated with these rights.

\section{Takedown policy}

If you believe that this document breaches copyright please refer to the University of Manchester's Takedown Procedures [http://man.ac.uk/04Y6Bo] or contact uml.scholarlycommunications@manchester.ac.uk providing relevant details, so we can investigate your claim.

\section{OPEN ACCESS}




\section{Witnessing workplace bullying and employee well-being: A two-wave field}

\section{study}

Christine A. Sprigg (c.a.sprigg@sheffield.ac.uk) Corresponding Author) Institute of Work Psychology, Sheffield University Management School, University of Sheffield, Sheffield, S10 1FL, UK.

Karen Niven, (Karen.niven@ manchester.ac.uk) PMO Organisational Psychology, Alliance Manchester Business School, The University of Manchester, Oxford Road, Manchester, M13 9PL, UK.

Jeremy Dawson (j.f.dawson@ sheffield.ac.uk) Institute of Work Psychology, Sheffield University Management School, University of Sheffield, Sheffield, S10 1FL, UK.

Samuel Farley (S.J.Farley@leeds.ac.uk) Leeds University Business School, Maurice Keyworth Building, The University of Leeds, Leeds, LS2 9JT. UK

Christopher Armitage, (chris.armitage @ manchester.ac.uk) Division of Psychology \& Mental Health, The University of Manchester, Oxford Road, Manchester, M13 9PL, UK. 


\section{Witnessing workplace bullying and employee well-being:}

\section{A two-wave field study}

This paper aims to: (a) explore the impact of witnessing workplace bullying on emotional exhaustion, work-related anxiety and work-related depression; and (b) determine whether the resources of trait optimism, co-worker support, and supportive supervisory style buffer the effects of witnessed bullying. In a two-wave study involving 194 employees, we found that witnessing bullying undermined employees' well-being (work-related depression and anxiety) six months later, but only if the employees were low in optimism (personal resource) and lacked supervisor support (contextual resource). Strong co-worker support weakened the relationship between witnessing bullying and well-being (emotional exhaustion and work-related depression). Our findings demonstrate for the first time some of the factors that protect against the impact of witnessing workplace bullying. Future research should focus on the development of workplace interventions that foster feelings of social support and optimism among employees.

Keywords: Witnessing bullying; Bullying bystanders; Well-being; Social support; Optimism 


\section{Witnessing workplace bullying and employee well-being:}

\section{A two-wave field study}

Working in an organisation where colleagues are bullied is likely to have long-term effects on people's psychological health. Research over the past 20 years has established that being personally subjected to bullying has negative consequences for individuals (Verkuil, Atasayi \& Molendijk, 2015). More recently, an emerging body of research indicates that it is not just those on the receiving end of bullying who may suffer; merely witnessing bullying could also have negative consequences for employees (e.g., Emdad, Alipour, Hagberg \& Jensen, 2013a). However, to date the threats to employee well-being emanating from witnessing bullying have been obscured by issues of methodological design (Nielsen \& Einarsen, 2013) and little is known about whether personal characteristics or features of the work environment could protect people from such threats. Given that third party witnesses to bullying far outnumber targets, research on this topic has the potential to provide important insights into the well-being of the larger work unit (Namie \& Lutgen-Sandvik, 2010).

Our study aims to investigate the relationship between witnessing workplace bullying and psychological well-being. Drawing on the stressor-strain appraisal theory (Lazarus, 1991) and conservation of resources (COR) theory (Hobfoll, 1989), we propose that employees' resources can influence the extent to which their well-being is affected by witnessing bullying at work. Specifically, we argue that the effects of witnessing bullying on employees' well-being emanate from a two-stage appraisal process in which employees appraise the situation or event they have witnessed and whether it poses a threat to them (primary appraisal), and then assess whether they are able to deal with what they have witnessed (secondary appraisal). The availability of both personal and contextual resources can therefore attenuate the detrimental effects that would be expected from the stressor of 
witnessing workplace bullying, by positively influencing people's perceptions of the threat posed by witnessed bullying at the primary appraisal stage and their ability to cope at the secondary appraisal stage.

Our study contributes to the literature by examining a relatively novel stressor, namely, witnessing workplace bullying. While a few studies have already reported associations between witnessing bullying and poor well-being, issues of methodological design have hampered this research area. As explained by Nielsen and Einarsen (2013), failure to partial out the effects of experienced bullying in prior research may confound the effects of witnessing bullying, because there is a large overlap between observed and experienced bullying, meaning that the associations observed between witnessing bullying and poor well-being may simply be due to witnesses additionally being exposed directly to bullying as victims. Likewise, the cross-sectional nature of prior research means that it is possible that instead of witnessing bullying causing poor well-being, those workers who experience psychological distress may simply be more likely to perceive negativity (e.g., bullying amongst colleagues) in their work environments. Here, we adopt a more rigorous methodological design, wherein we control for people's experiences of actually being subjected to bullying and use cross-lagged data over a six-month period, to provide greater insight into the strength and duration of the effects of witnessing bullying.

Our study also adds nuance by testing the idea that the extent to which employees' well-being is affected by witnessing bullying will vary depending on their resources. There has been minimal research examining the psychological buffers of experiencing workplace bullying (Plopa, Plopa \& Skuzińska, 2017) and no research focusing on buffers of witnessing bullying. Here, we focus on optimism, coworker support, and supportive supervisory style as possible buffers. authoritative version of the article. Please do not copy or cite without authors' permission. The final article will be available, upon publication, via its DOI: 10.1037/ocp0000137 


\section{Background and Study Hypotheses}

Workplace bullying is defined as a situation where over time an employee persistently perceives him or herself as being on the receiving end of negative actions from others from inside or outside the organisation while at work and find it difficult to defend him or herself against these actions (Einarsen \& Skogstad, 1996). Researchers maintain that the definitional characteristics of bullying distinguish it from other forms of workplace aggression, such as workplace incivility or violence (Nielsen, Hoel, Zapf \& Einarsen, 2015). Notably, bullying involves the targeted person being subjected to persistent mistreatment over a long period of time. During this process, the target lacks the ability to defend themselves against mistreatment, which implies a relative lack of power compared to the perpetrator.

Although those who witness bullying directed towards coworkers may not actually be subjected to such mistreatment themselves, we expect that merely seeing others in one's organisation being bullied is sufficient to produce psychological ill effects. This proposition is consistent with the stressor-strain framework (Lazarus, 1991), which posits that stressful events (i.e., stressors) are appraised by those who encounter them and, if the events are viewed as threats then a stress appraisal may be elicited, in turn leading to a strain-type response (e.g., poorer well-being). A situation like witnessed bullying is an indication of how people in one's organisation are treated and, as such, it represents how a person oneself might be treated in the future. Thus, the event is personally relevant and implies negative consequences for the focal person, making it a potential threat. Given the persistent nature of workplace bullying, witnesses may observe multiple acts over a period of time, which will likely produce a greater threat perception than seeing one or two isolated events (Kane \& Montgomery, 1998). Accordingly, as bullying situations unfold, and witnesses continuously appraise bullying events, they will likely experience more and more strain. The power 
imbalance implicit in the bullying process may also lead witnesses to feel more threatened than they would when viewing a conflict between two parties of equal standing, because high-powered individuals have the ability to influence the opinions and behaviours of others in the workgroup (Hershcovis, Reich, Parker, \& Bozeman, 2012).

In line with these arguments, several studies have begun to suggest associations between witnessing workplace bullying and poor well-being. For example, Vartia (2001) found that observers of bullying reported more stress reactions than employees from work environments free of bullying. Lutgen-Sandvik, Tracy, and Alberts (2007) similarly observed that witnesses of workplace bullying had greater stress and lower satisfaction levels than those who had not been targeted or witnessed bullying (although lower stress and higher satisfaction than targets themselves). Totterdell, Hershcovis, Niven, Reich, and Stride (2012) further reported that witnessing negative acts between colleagues was associated with emotional exhaustion. Finally, Emdad and colleagues (2013a) found that being a bystander to workplace bullying increased the risk of developing symptoms of depression 18 months later. However, there has been some debate within the literature about whether witnessing bullying truly represents a stressor, due to issues of methodological design in this prior research. Notably, Nielsen and Einarsen (2013) found that a baseline measure of psychological distress predicted increased rates of witnessing bullying two years later, whereas the impact of witnessing bullying on psychological distress disappeared after controlling for experienced bullying. They concluded that distressed workers may perceive their working conditions more negatively than other employees and hence be more likely to notice bullying or to appraise the interpersonal behaviours they observe as threats (the socalled 'gloomy perception mechanism'; De Lange et al., 2005). Moreover, because there are strong overlaps between people's experiences of being subjected to and witnessing bullying authoritative version of the article. Please do not copy or cite without authors' permission. The final article will be available, upon publication, via its DOI: 10.1037/ocp0000137 
in the workplace (Hauge, Skodstad, \& Einarsen, 2007), and it is known that being subjected to bullying has substantial detrimental effects on well-being (Verkuil et al., 2015), this might explain the associations reported between witnessing bullying and poor well-being in other studies. Accordingly, there is a need for research examining the longitudinal associations between witnessed bullying and well-being, and especially for studies exploring whether these associations hold over and above the effects of actually being subjected to bullying.

In the present research, we explore the longitudinal associations between witnessed aggression and three indicators of well-being. Work-related depression and anxiety have been proposed by Warr (1990) among others as key indicators of affective well-being that represent unpleasant states that are either high (anxiety) or low (depression) in activation. These states concern how individuals feel in their jobs, rather than clinical syndromes. Emotional exhaustion is considered the key component of burnout, which refers to "a prolonged response to chronic emotional and interpersonal stressors on the job" (Maslach, Schaufeli, \& Leiter, 2001, p. 397), with emotional exhaustion specifically regarding feelings of being drained by one's job. Specifically, we propose:

Hypothesis 1: Witnessing bullying at Time 1 will be positively related to (a) workrelated depression, (b) work-related anxiety, and (c) emotional exhaustion at Time 2 six months later (after controlling for experienced bullying).

\section{Resources as Moderators of the effects of Witnessed Bullying}

While some studies have linked witnessing bullying with psychological ill health, little is known about the moderators of this association. However, theoretically at least, there is good reason to believe that not everyone who witnesses workplace bullying will necessarily develop poorer well-being. Lazarus's (1991) stressor-strain framework suggests that people's responses to potential stressors, like witnessed bullying, are dependent upon 
how they appraise these events. In particular, Lazarus suggests that people undergo a twostage appraisal process. At the primary appraisal stage, people's focus is on whether the event in question is a personal threat, i.e., something that is relevant to their goals and that would have negative consequences for them. Assuming that a threat appraisal is elicited at this first stage, a secondary appraisal stage is posited, in which people's focus turns to their ability to cope with the threat. If a person perceives that he or she is able to deal with the threat, the threat is effectively neutralised and no ill effects are expected. Conversely, if a person perceives that he or she is unable to cope then poor psychological well-being will ensue. As such, any factor that influences either of these appraisals would theoretically influence the relationship between witnessed bullying and psychological well-being.

One likely set of factors that could positively influence the appraisal process, by reducing people's perceptions of stressors as threats, and by improving people's perceptions of their ability to cope with stressors, is resources. Hobfoll's (1989) conservation of resources (COR) theory states that individuals are motivated to protect and accumulate resources, which are "those objects, personal characteristics, conditions, or energies that are valued by the individual or that serve as a means for attainment of these objects, personal characteristics, conditions, or energies" (p. 516). While COR explains that loss of resources causes individuals to experience strain, resources may also serve as a buffer to strain because of their impact on people's appraisals. Although Hobfoll describes a large amount of possible resources, here we focus our attention on three resources that we expect to be particularly relevant in the context of witnessed bullying: optimism, coworker support, and supportive supervisory style. Our choice of resources therefore covers the range of factors thought to be potentially influential in determining the consequences of bullying, as noted by Nielsen and Einarsen (2018), who stated that "Theoretically, it is likely that the effects of bullying are authoritative version of the article. Please do not copy or cite without authors' permission. The final article will be available, upon publication, via its DOI: 10.1037/ocp0000137 
dependent upon a range of... characteristics such as individual dispositions and resilience, coping behaviors, social support, and leadership practices" (p. 29, emphasis added).

\section{Optimism as a Personal Resource}

The first resource we examine is optimism. Optimism is a personal resource reflecting the extent to which people hold positive future expectancies (Carver, Scheier \& Segerstrom, 2010). From a COR perspective, those with high optimism are more likely to be protected from psychological ill health after witnessing workplace bullying for two key reasons. First, optimism is likely to influence the primary appraisal stage, making people less likely to view witnessed bullying as a personal threat. Optimists perceive events more positively and are inclined to expect positive outcomes. Therefore they may be less likely to worry that the person enacting bullying against a co-worker will start bullying them and more likely to expect that the bullying they witness will be resolved. Second, optimism is likely to positively influence people's perceptions of their ability to cope at the secondary appraisal stage, because an optimistic disposition has been linked to the adaptability levels needed to cope with threatening situations (Aspinwall \& Taylor, 1992). In support of the buffering effect of optimism, previous research has highlighted that optimism can attenuate the effects of a variety of stressors (e.g., Carver et al., 2010). Accordingly, we hypothesise:

Hypothesis 2: Trait optimism will buffer the relationship between witnessing workplace bullying (Time 1) and all three psychological well-being outcomes a) work-related depression, b) work-related anxiety, and c) emotional exhaustion) at Time 2.

\section{Support as a Contextual Resource}

The second and third resources we focus on are social support from coworkers and supportive supervisory style, respectively. We expect that support should buffer the effects of 
witnessed bullying due to its impact on the secondary appraisal stage, in which employees evaluates their ability to cope with a potential stressor (Lazarus, 1991), because it promotes a positive 'sense of self' and a view that one can overcome stressful situations (Hobfoll, 1989). There is some debate within the social support literature about whether or not support is always a buffer against stressors, with some previous studies suggesting null effects of this resource and some even finding that the effects of stressors are exacerbated in the presence of high support (Beehr, Farmer, Glazer, Gudanowski, \& Nair, 2003). However, we believe that support is likely to be an important buffering resource when it comes to the specific stressor of witnessing workplace bullying because, as Hobfoll (1989) outlines, support is most beneficial when it provides for situational needs. The experience of witnessing bullying is a situation where a strong need for social support is likely to arise because fears of being personally targeted in the future may be evoked, leading to a need to know that others in the workplace do care about one's well-being (Djurkovic, McCormack, \& Casimir, 2008).

We expect that coworkers and supervisors can both be valuable sources of support that aid employees' perceptions of their coping ability and therefore buffer the effects of witnessing bullying. Coworkers might be seen as a more common source of support, given that bullying witnesses report receiving greater support from their coworkers than from their supervisors (Hansen et al., 2006), and that those in a managerial role are actually the most frequent perpetrators of bullying (Rayner, Hoel \& Cooper, 2002). Yet support from supervisors via their leadership style, even if less frequent, may be particularly powerful, as suggested by meta-analytic evidence, which revealed that the negative relationship between social support and exhaustion is stronger when the support is offered by supervisors, as opposed to co-workers (Halbesleben, 2006). On this basis, we hypothesise the following: authoritative version of the article. Please do not copy or cite without authors' permission. The final article will be available, upon publication, via its DOI: $10.1037 /$ ocp0000137 
Hypothesis 3: Social support from coworkers (Time 1) will buffer the relationship between witnessing workplace bullying (Time 1) all three psychological well-being outcomes a) work-related depression, b) work-related anxiety, and c) emotional exhaustion) at Time 2.

Hypothesis 4: Supportive supervisory style (Time 1) will buffer the relationship between witnessing workplace bullying (Time 1) and all three psychological wellbeing outcomes a) work-related depression, b) work-related anxiety, and c) emotional exhaustion) at Time 2 .

\section{Method}

\section{Participants and Procedure}

Data were collected by means of an electronic survey administered at two points in time with a lag of approximately six months in between. Responses to the survey were anonymous and matched using unique identification codes. We chose a lag of six months because researchers often cite this as the minimum period in which a bullying situation can develop (Nielsen et al., 2015). We adopted a broad sampling strategy, informed by existing research on prevalence of bullying across occupation types. In particular, we sought to gain representation from occupations known to have relatively higher prevalence rates of bullying, in order to maximise the chances of our participants having witnessed bullying over the period studied. For example, in line with Ortega, Høgh, Pejtersen, and Olsen (2009), we were keen to attain representation from service workers, protective service workers (e.g., fire fighters), teaching professionals, social workers, health care workers, and drivers, among other occupations. We mainly used existing networks from members of the research team, but also made new contacts in several organisations for the purposes of attaining representation as described above. In all, we approached around 30 UK-based organisations, 
of which, after a concerted effort, 10 initially accepted our invitation to participate in the two stages of research. One of these organisations was then lost at a late stage, because two key contacts left the organisation. This resulted in a final sample of nine organisations.

We prepared an email with our survey link and asked key stakeholders (e.g., human resources managers, union leaders) from the participating organisations to distribute the email to employees. Most organisations used this email to let employees know about the survey, but some organisations where few workers made regular use of work email accounts additionally used a brief advertisement in their newsletters as a means to gather participants. A total of 3,652 people responded to the first survey (note that we cannot accurately estimate a response rate, as we have no means of determining how many people our initial emails were sent to or how many people had access to newsletters). Most respondents were from public administration/defence $(n=1,594)$, followed by health and social work $(n=462)$, education $(n=394)$, and community services $(n=268)$. The mean age was 43 years $(S D=10.35)$, the sample comprised 1854 females $(63.1 \%)$, and the sample was $92.2 \%$ white ethnicity.

At the second time point, we again asked our stakeholders to distribute a new email with a link to the second survey or to re-advertise the survey in their newsletter. This approach yielded 194 participants whose responses we could match across both time points. These 194 participants made up the final sample for our analysis. In total, 59.3\% of the final sample were female; $90.7 \%$ were White (with $4.6 \%$ Asian, $1 \%$ Black and $2.6 \%$ other); $18 \%$ worked in education, $33 \%$ in public administration/defence, $39.2 \%$ in health and social work, $7.7 \%$ in other community/social organizations (including emergency services), and $2.1 \%$ in other types of organization. Regarding professional role, $5.2 \%$ were senior managers, $26.3 \%$ were middle managers, and $65.5 \%$ were workers (with $3 \%$ saying "other" or not responding). authoritative version of the article. Please do not copy or cite without authors' permission. The final article will be available, upon publication, via its DOI: 10.1037/ocp0000137 
The mean age was 44.4 years $(\mathrm{SD}=9.4)$, mean tenure was 13.64 years $(\mathrm{SD}=9.82)$, and the vast majority of respondents worked full time (93.8\% worked over 30 hours per week).

The reduction in our sample size between the first and second waves of data collection is likely accounted for by a combination of differences in the email lists accessed by our stakeholders between the two waves, differences in distribution and reading habits relating to newsletters and, to a lesser degree, changes in personnel within participating organisations. To ascertain whether there were any systematic differences between those who stayed in the survey and those who exited after the wave one survey, we conducted attrition analysis on the witnessing bullying, experienced bullying and demographic variables. The analyses showed no significant differences between study stayers and leavers with respect to any variables, with the exception of organisational sector $(\chi 2=89.04, \mathrm{df}=10, \mathrm{p}<.001)$; those who completed both surveys were more likely to work in health/social care and education, but less likely to work in public administration and defence. These results suggest few systematic differences between those who only completed the initial survey and those who completed the follow-up survey.

\section{Measures}

We decided to shorten established scales in order to maximise participation rates, as attrition can be an issue with longer surveys, especially when seeking to retain a longitudinal sample. Below, we describe the measures used and adaptations we made from original scales. Broadly, our strategy when adapting scales was to ensure full coverage of each construct, by including representative items from all sub-factors.

\section{Witnessed Bullying at Work}

We adapted items from the Negative Acts Questionnaire (NAQ; Einarsen \& Raknes, 1997) to assess witnessed bullying at work. Each item was adapted to relate to witnessed 
rather than experienced bullying. We selected six items, seeking coverage from the personrelated, work-related and physically intimidating factors of the measure (see Appendix). In the scale, participants were asked to indicate how often they had witnessed others at work being subjected to each of these 6 acts over the last six months, by any other individual (including coworkers, supervisors, and people external to the organisation, such as customers or clients). We used a five-point frequency-based response scale, ranging from 'never' to 'daily' (time $1 \alpha=.84$; time $2 \alpha=.85$ ).

\section{Well-being}

Work-related depression and anxiety were captured using the short form of Warr's (1990) scales. While Warr's original scales each have six items (including both positivelyand negatively-worded items), the short form scales, comprising only the three negativelyworded items, have been widely used and validated (e.g., Stride, Wall, \& Catley, 2008). Respondents were asked: Over the last six months, how much of the time has your job made you feel... "Miserable", "Depressed", and "Gloomy" (depression: time $1 \alpha=.95$; time $2 \alpha=$ .95 ) and "Tense", "Worried", and "Uneasy" (anxiety: time $1 \alpha=.91$; time $2 \alpha=.93$ ). We used a five-point frequency-response scale, ranging from 'never' to 'all of the time'.

Emotional exhaustion was measured using the three highest loading items from the emotional exhaustion subscale of the Maslach Burnout Inventory (Maslach \& Jackson, 1986). Respondents were asked: How often have you experienced the following over the past six months? "I feel emotionally drained from my work", "I feel used up at the end of the workday", and "I feel burned out from my work" (time $1 \alpha=.93$; time $2 \alpha=.95$ ). Participants responded on a seven-point scale (from 'never' to 'daily'). We selected a timescale of six months for the well-being measures in order to match the timescale of witnessed well-being.

\section{Resources}


We measured the three resources in the Time 1 survey only. Trait optimism was assessed using three-items from the Life Orientation Test (LOT; Luthans, Youssef, \& Avolio, 2007), with a mixture of positively- and negatively-worded items selected, to represent the two factors observed within the original scale. The items used were: "I'm always optimistic about my future", "I hardly ever expect things to go my way", and "I rarely count on good things happening to me" $(\alpha=.81)$. Responses were on a five-point scale from 'strongly disagree' to 'strongly agree'.

Coworker social support was measured with three-items covering both emotional and instrumental support types taken from a scale developed by Caplan, Cobb, and French (1975). The items we used were: "I feel I can talk to my colleagues about personal problems", "I can rely on my colleagues to help me out with work problems", and "I can talk to my colleagues about things that upset or annoy me at work" $(\alpha=.87)$. Supportive supervisory style was measured using three items from O'Hara (1999): “I feel safe to voice my opinions to my manager", "My manager has an open and honest management style", and "My manager deals with mistakes in a non-threatening manner" $(\alpha=.94)$. Responses to both support scales were on a five-point scale from 'strongly disagree' to 'strongly agree'.

\section{Control Variables}

In order to establish whether the effects of witnessed aggression hold over and above experienced bullying, we measured participants' direct experiences of being bullied in the Time 1 survey. To do this, we used the equivalent six items from the NAQ that were used in the witnessing measure, however respondents were asked about the extent to which they themselves had experienced this behaviour from someone in their organisation. An example item is "being shouted at or target of spontaneous anger" $(\alpha=.76)$. We used the same fivepoint frequency-based response scale, ranging from 'never' (1) to 'daily' (5). We also 
controlled for age, gender, and organisational tenure in the Time 1 survey, because the outcomes of interest in our study have all been found to vary according to these demographic variables in previous research (Stride et al., 2008).

\section{Analysis}

We tested our hypotheses using regression analysis in Mplus version 7. Due to missing data on variables of interest, we employed Full Information Maximum Likelihood (FIML) estimation. FIML uses all the available data contained in cases to produce estimates of missing values, thus making the most efficient use of the data (Newman, 2003). For our main effects analysis, we tested for the effects of witnessed bullying over time, using witnessed bullying measured at Time 1 as the predictor variable, well-being variables measured at Time 2 as our outcomes, and controlling for age, gender, organizational tenure, experienced bullying, and Time 1 well-being. For the moderation analysis we followed the guidelines of Dawson (2014), with all independent variables being z-standardized before being entered (other than the binary variable, gender). Again, we controlled for the same variables. In order to avoid problems caused by multi-collinearity between multiple correlated variables we examined the effect of each moderator separately for each outcome.

\section{Results}

\section{Preliminary Analyses}

Table 1 shows the means, standard deviations and intercorrelations of all study variables (including control variables). There were some high correlations between the three outcomes, as well as between the three moderators. Therefore, we tested these measures for discriminant validity using the Average Variance Explained (AVE) test within confirmatory factor analysis (CFA) (Fornell \& Larcker, 1981). 
A CFA of the moderators and Time 2 outcome variables indicated good model fit $(\mathrm{CFI}=0.97 ; \mathrm{TLI}=0.96 ; \mathrm{SRMR}=.05)$. The AVEs for the three moderators were 0.60 (optimism), 0.85 (supportive supervisory style) and 0.69 (co-worker social support). These were all larger than the squared correlations between factors, the largest of which was 0.24 (between optimism and co-worker social support). The AVEs for the outcomes were 0.86 (emotional exhaustion), 0.85 (depression) and 0.83 (anxiety). ${ }^{1}$ The highest squared correlation was 0.66 (between emotional exhaustion and depression). These analyses clearly satisfy the criteria for discriminant validity between the moderators and outcome variables.

\section{Effects of Witnessed Bullying on Well-being}

Hypothesis 1 proposed that witnessed bullying would be positively related to poor well-being. While the zero-order correlations displayed in Table 1 show that witnessed bullying at Time 1 was significantly associated with well-being outcomes measured at Time 2, witnessed bullying was no longer significantly related to any of the well-being outcomes when age, gender, organisational tenure, well-being at Time 1, and experienced bullying were controlled for (Table 2). Therefore hypothesis 1 was not supported. To test for reverse causality, three further regression analyses were conducted using the Time 1 well-being variables as predictors and witnessed bullying measured at Time 2 as the outcome. Age, gender, organisational tenure, witnessed bullying and experienced bullying (all at Time 1) were again used as control variables. These analyses found no significant effects of any of the

\footnotetext{
${ }^{1}$ An equivalent analysis suggested that Time 1 outcome variables similarly showed discriminant validity. 17 authoritative version of the article. Please do not copy or cite without authors' permission. The final article will be available, upon publication, via its DOI: 10.1037/ocp0000137
} 
well-being variables on subsequent witnessed bullying (depression beta $=.03, \mathrm{p}=.62$;

anxiety beta $=.02, \mathrm{p}=.81$; emotional exhaustion beta $=.01, \mathrm{p}=.88)$.

Insert Table 2 here

\section{Impact of Resources on the effects of Witnessed Bullying}

Hypotheses 2, 3 and 4 predicted moderating effects of resources on the relationship between witnessing workplace bullying (Time 1) and psychological well-being (Time 2), such that the relationship between witnessing bullying and poor well-being would be buffered at high levels of optimism (H2), coworker social support (H3), and supportive supervisory style (H4). Our results (Table 3) indicated that optimism significantly moderates the impact of witnessing bullying on work-related depression and anxiety, but not on emotional exhaustion. The interactions were in the expected direction, as illustrated in Figure $1 .^{2}$ Therefore hypothesis 2 is partially supported. In support of hypothesis 3, our results also revealed that social support from coworkers significantly moderates the impact of witnessing bullying on emotional exhaustion and workplace depression, but not on anxiety. Again, the interactions were in the expected direction, as illustrated in Figure 2. Finally, our results showed that supportive supervisory style significantly buffered the impact of witnessing bullying on work-related depression and anxiety, but not on emotional exhaustion (see Figure 3 for an illustration). Accordingly, hypothesis 4 is partially supported.

Insert Table 3 here

\footnotetext{
${ }^{2}$ Copies of all interaction plots can be accessed in the online supplementary materials. authoritative version of the article. Please do not copy or cite without authors' permission. The final article will be available, upon publication, via its DOI: 10.1037/ocp0000137
} 


\section{Exploratory Analyses}

A set of supplementary analyses was conducted to explore whether the resource variables we measured would also buffer the impact of experiencing workplace bullying. Here, we tested whether resources moderated the impact of experiencing bullying (Time 1) on emotional exhaustion, depression and anxiety (Time 2), when age, gender, tenure and well-being at Time 1 were all controlled for. The results suggest some evidence of a similar buffering effect. ${ }^{3}$ In particular, optimism moderated the relationship between experiencing bullying and all three well-being variables, while co-worker social support and supportive supervisory style moderated the relationship between experiencing bullying and work-related depression, although not emotional exhaustion or work-related anxiety. The interactions were all in a direction consistent with a buffering effect.

\section{Discussion}

In this study, we sought to examine the impact of witnessing bullying on employee psychological well-being. Previously researchers have identified a significant relationship between witnessing bullying and lower levels of psychological health (e.g., Emdad et al, 2013a). However, it has been argued that this relationship can be explained by witnesses' own bullying exposure and by reverse causal effects (Nielsen \& Einarsen, 2013). Researchers therefore argue that studies on witnesses should always control for experienced bullying and should study the effects of witnessing bullying over time (Emdad et al, 2013b). Consistent with this emerging body of research, we found no significant relationship between witnessing bullying and psychological well-being six months later once we had controlled for

\footnotetext{
${ }^{3}$ The full findings of these analyses are available as supplementary online materials. 
experienced bullying. There was also no reverse causal effect, suggesting that employees with lower levels of psychological well-being were not more likely to appraise workplace interactions as hostile.

However, our moderation analyses qualified these results, revealing that witnessing bullying does have an impact on people's well-being six months later, even when their experiences of being subjected to bullying are controlled for, but only for certain people, namely those lacking in particular personal and contextual resources. Previous studies have not considered the idea that certain employees may be more or less susceptible to the negative effects of witnessing bullying. Our findings show that for people low in trait optimism and those who lacked social support from their co-workers or whose supervisors lacked a supportive leadership style, witnessing bullying did predict future poor well-being. We theorised that these particular resources would be important in the context of witnessing bullying, based on insights from stressor-strain theory (Lazarus, 1991) and conservation of resources (COR) theory (Hobfoll, 1989). Specifically, we expected the resources we studied would either influence how employees appraise witnessed bullying (e.g., not viewing it as a personal threat) or how they appraise their ability to cope with witnessed bullying.

We did not observe all the moderation effects we had predicted. Contrary to our expectations, optimism did not moderate the impact of witnessing bullying on emotional exhaustion, which suggests that it may play a greater role in preventing work-related anxiety and depression than in preventing symptoms of burnout. Furthermore, co-worker support did not moderate the relationship between witnessing bullying and anxiety, while supportive supervisory style did not affect the relationship between witnessing and emotional exhaustion. Whilst it is difficult to determine why these different sources of contextual support lead to these specific relationships here, it is evident our findings reflect some authoritative version of the article. Please do not copy or cite without authors' permission. The final article will be available, upon publication, via its DOI: 10.1037/ocp0000137 
important distinctions between these sources of support when it comes to witnessing bullying in the workplace.

Our exploratory analyses indicated that the resources we propose as buffers could be applicable in circumstances where employees experience bullying, rather than witnessing it. This constitutes an important insight because many researchers have until now implicitly assumed that being subjected to bullying may affect all employees equally, and few have considered whether personal resources or resource-enhancing aspects of the work environment context might reduce people's susceptibility to experiencing ill effects.

\section{Theoretical Contributions}

Our paper makes a number of important contributions to the workplace bullying research domain. First, we establish witnessing workplace bullying as a novel stressor that can have a damaging impact on employee well-being. As noted earlier, the methodological limitations of prior research have likely obscured the true effects of this stressor (Nielsen \& Einarsen, 2013). Our more rigorous study design has confirmed that witnessing bullying does negatively affect employees' well-being over time, over and above the effects of being subjected to bullying, but only under certain circumstances.

Second, by integrating existing theories of stress (i.e., the stressor-strain model; Lazarus, 1991, and COR theory, Hobfoll, 1989), we have added nuance to the bullying literature by proposing and testing the idea that witnessing bullying at work may not always lead to negative well-being outcomes. In particular, we have been able to identify specific resources that make employees more equipped to cope with witnessed workplace bullying, i.e., trait optimism, social support from coworkers, and supportive supervisory style. Our empirical results show that it is only in the absence of these resources that witnessing bullying appears to have a detrimental effect on workers' well-being, suggesting that the role 
played by resources such as these may be extremely central in determining how workers respond to witnessing bullying in their organisational environment.

Third, our research also highlights some potential buffers of the negative well-being effects associated with experienced workplace bullying. There is a paucity of research on moderators in this area (Nielsen \& Einarsen, 2018), suggesting an implicit assumption that being subjected to bullying might affect all workers equally, but our exploratory results suggest that this might not be the case. Instead, the same resources that buffer the effects of witnessed bullying might also help to make those who are actually subjected to bullying less susceptible to experiencing negative well-being consequences, presumably because they alter victims' appraisals about the threat posed by bullying and their ability to cope with this threat. This echoes recent research by Hewett, Liefooghe, Visockaite, and Roongrerngsuke (2018), who suggest that it is the interaction between experiencing negative acts and coping strategies that goes on to define the outcomes. Taken together, our findings highlight that the resources in our study, which have been shown to buffer other stressors in previous research (e.g., Beehr et al., 2003; Carver et al., 2010), are similarly important buffers of the stressors of witnessing and experiencing workplace bullying.

\section{Limitations}

Our research was robust and conservative in research design. Nevertheless, the study has limitations. Although we attempted to get a good matched response rate at Time 2, we experienced high rates of attrition over the course of our study, resulting in a somewhat low sample size (though adequate for detecting moderately large interaction effects; Shieh, 2009). While our attrition analysis shows limited differences between those who completed both parts of the survey and those who left after the Time 1 survey in terms of demographics and core study variables, it is still possible that there may be differences between stayers and 
leavers on unmeasured variables that we did not consider. Our sampling strategy might also raise questions over the generalisability of our findings, given that we intentionally sampled from occupations where researchers have previously reported somewhat high prevalence rates of bullying (Ortega et al., 2009). However, the actual bullying prevalence in our sample (in terms of participants' reports of direct exposure to bullying behaviours) was similar to that reported in other UK samples (e.g., Coyne, Smith-Lee Chong, Seigne, \& Randall, 2003), suggesting that no obvious reason why our results would not generalise.

In addition, in order to reduce the load on participants, we shortened established measures in order to assess our central constructs, which may have compromised the validity of the measures. However, we ensured that we selected items representing the full range of each construct captured (e.g., for the NAQ, we selected items from each of the personrelated, work-related and physically intimidating factors), and the resulting scales showed good internal consistency.

\section{Practical Implications}

Our findings demonstrate two important ways to potentially limit the impact of witnessed bullying on employee well-being. First, an employee feeling that both their coworkers and supervisors genuinely support them is clearly a vital part of any organisational damage limitation strategy for bullying. Thus, individuals should be encouraged to create positive informal social relationships, characterised by mutual appreciation and reciprocity (see Dutton \& Ragins, 2007). Leaders and supervisors through their position as role models can promote such positive relationships; they should actively support their employees and encourage employees to support each other. Organisations must also strive to create working cultures of 'mutual appreciation', wherein the work environment is one that encourages collaboration, with employees not afraid to seek support and able to do so without punitive 
risk. Research also suggests that employees perceive greater support in their environment when they are actively involved in decision-making in matters that impact their jobs directly (Rhoades \& Eisenberger, 2002). By drawing on ideas and techniques such as these, organisations and managers can therefore create more supportive environments that help to inoculate employees against the ills of toxic work cultures.

Second, our findings highlight the practical importance of developing employees' optimism in order to help protect employees if they are to witness bullying at work. While optimism might appear on the surface not to be particularly malleable, Seligman (2011) has previously argued that people obtain a sense of optimism through learning and that trait optimism may therefore be developed. Lu, Xie, and Guo (2018) have proposed that leaders and managers in particular can have a profound impact on employee optimism, suggesting that employees learn to be more optimistic when their leaders exhibit greater work engagement, because leader engagement offers a model to employees about how work can be a contributor to their well-being. Thus work engagement interventions for leaders could potentially provide one means through which employee optimism could be enhanced.

\section{Future Research}

Our study shows that resource moderators matter when it comes to witnessed bullying, yet the research literature is far from replete with studies examining such possible moderators. We suggest that future research gathers more information on the full range of personal or contextual resources that buffer against the negative effects on employees. For example, it could be fruitful to examine aspects such as resilience, positive affectivity, agreeableness, autonomy, and work engagement.

In addition, we advocate greater exploration of the role of personal optimism in buffering the effects of witnessed and experienced bullying. At least one previous study has 
reported that optimism may actually exacerbate the negative effects of bullying type behaviours. Britton, Sliter, and Jex (2012) argued that optimism might bias people's perspectives, creating unrealistic expectations, and that when these expectations are not met (for instance, a bullying situation does not get resolved) the negative reaction to mistreatment may be heightened. Future research could therefore explore the differentiation between realistic versus unrealistic optimism (Schneider, 2001), in order to ascertain when optimism may help or hinder victims and witnesses of workplace bullying. Similarly, greater insight into the role played by social support could be gained by giving attention to the source of bullying when examining the moderating effects of social support, in order to explore whether there are divergent consequences when the source of bullying and of social support are one and the same versus different people (Duffy, Ganster, \& Pagon, 2002).

Finally, future research might explicitly test the mechanisms of the moderators we have examined here. We have theorised that the resources we examined would either influence employees' primary appraisals of bullying as either threatening or employees' secondary appraisals of their perceived ability to cope with such threat. Thus, we recommend that researchers measure our implied mechanisms in novel experimental and field studies.

\section{Conclusion}

We have developed a theoretical framework to better understand the impact of witnessed bullying at work. Our combined two-stage model guides researchers in providing valuable insight into the psychological impact of witnessed bullying at work by identifying conditions under which witnessed bullying does and does not have a negative effect on the well-being of employees. We find that personal and work context resources of optimism, coworker support, and supportive supervisory style protect employees from the ill-effects of 
witnessing bullying. Our findings add to a growing body of research on the importance of understanding the impact of merely witnessing of negative events at work.

(c) 2018, American Psychological Association. This paper is not the copy of record and may not exactly replicate the final, authoritative version of the article. Please do not copy or cite without authors' permission. The final article will be available, upon publication, via its DOI: 10.1037/ocp0000137 


\section{References}

Aspinwall, L., \& Taylor, S. (1992). Modeling cognitive adaptation: A longitudinal investigation of the impact of individual differences and coping on college adjustment and performance. Journal of Personality and Social Psychology 62(6): 989-1003.

Beehr, T. A., Farmer, S. J., Glazer, S., Gudanowski, D. M., \& Nair, V. N. (2003). The enigma of social support and occupational stress: Source congruence and gender role effects. Journal of Occupational Health Psychology, 8(3), 220-231.

Britton, A. R., Sliter, M. T., \& Jex, S. M. (2012). Is the glass really half-full? The reverse buffering effect of optimism on undermining behavior. Personality and Individual Differences, 52, 712-717.

Caplan, R. D., Cobb, S., \& French, J. R. (1975). Job demands and worker health; main effects and occupational differences. In Hew Publication (NIOSH) (Vol. 75). DHEW.

Carver, C.S., Scheier, M.F., \& Segerstrom, S.C. (2010). Optimism. Clinical Psychology Review, 30, 879-889.

Coyne, I., Smith-Lee Chong, P., Seigne, E., \& Randall, P. (2003). Self and peer nominations of bullying: An analysis of incident rates, individual differences, and perceptions of the working environment. European Journal of Work and Organizational Psychology, 12(3), 209-228.

Dawson, J. F. (2014). Moderation in management research: What, why, when, and how. Journal of Business and Psychology, 29(1), 1-19.

De Lange, A. H., Taris, T. W., Kompier, M. A., Houtman, I. L., \& Bongers, P. M. (2005). Different mechanisms to explain the reversed effects of mental health on work characteristics. Scandinavian Journal of Work, Environment \& Health, 3-14. 
Djurkovic, N., McCormack, D. \& Casimir, G. (2008). Workplace bullying and intention to leave: The moderating effect of perceived organisational support. Human Resource Management Journal, 18, 405-422.

Duffy, M. K., Ganster, D. C., \& Pagon, M. (2002). Social undermining in the workplace. Academy of Management Journal, 45(2), 331-351.

Dutton, J. E., \& Ragins, B. R. (Eds.) (2007). Exploring Positive Relationships at Work: Building a Theoretical and Research Foundation. London: Lawrence Erlbaum.

Einarsen, S., \& Raknes, B. I. (1997). Harassment in the workplace and the victimization of men. Violence and Victims, 12(3), 247-63.

Einarsen, S., \& Skogstad, A. (1996). Bullying at work: Epidemiological findings in public and private organizations. European Journal of Work and Organizational Psychology, $5,185-201$.

Emdad, R., Alipour, A., Hagberg, J., \& Jensen, I.B. (2013a). The impact of bystanding to workplace bullying on symptoms of depression among women and men in industry in Sweden: an empirical and theoretical longitudinal study. International Archives of Occupational Environmental Health, 86(6), 709-716.

Emdad, R., Alipour, A., Hagberg, J., \& Jensen, I. B. (2013b). Comment on" Can observations of workplace bullying really make you depressed? A response to Emdad et al. 2013" by Nielsen and Einarsen. International Archives of Occupational and Environmental Health, 86(6), 723-724.

Fornell, C., \& Larcker, D. F. (1981). Evaluating structural equation models with unobserved variables and measurement error. Journal of Marketing Research, 18, 39-50.

Halbesleben, J. R. (2006). Sources of social support and burnout: A meta-analytic test of the conservation of resources model. Journal of Applied Psychology, 91(5), 1134-45. authoritative version of the article. Please do not copy or cite without authors' permission. The final article will be available, upon publication, via its DOI: 10.1037/ocp0000137 
Hansen, M., Hogh, A., Persson, R., Karlson, B., Garde, A. H. \& Orbaek, P. (2006) Bullying at work, health outcomes, and physiological stress response. Journal of Psychosomatic Research, 60, 263- 72 .

Hauge, L. J., Skogstad, A., \& Einarsen, S. (2007). Relationships between stressful work environments and bullying: Results of a large representative study. Work \& Stress, 21(3), 220-242.

Hershcovis, M. S., Reich, T. C., Parker, S. K., \& Bozeman, J. (2012). The relationship between workplace aggression and target deviant behaviour: The moderating roles of power and task interdependence. Work \& Stress, 26(1), 1-20.

Hewett, R., Liefooghe, A., Visockaite, G., \& Roongrerngsuke, S. (2018). Bullying at work: Cognitive appraisal of negative acts, coping, wellbeing, and performance. Journal of Occupational Health Psychology, 23(1), 71-84.

Hobfoll, S. E. (1989). Conservation of resources: A new attempt at conceptualizing stress. American Psychologist, 44, 513-524.

Kane, K., \& Montgomery, K. (1998). A framework for understanding dysempowerment in organizations. Human Resource Management (1986-1998), 37(3-4), 263.

Lazarus, R. S. (1991). Emotion and Adaptation. Oxford University Press.

Lu, X., Xie, B., \& Guo, Y. (2018). The trickle-down of work engagement from leader to follower: The roles of optimism and self-efficacy. Journal of Business Research, 84, 186-195.

Lutgen-Sandvik, P., Tracy, S. J., \& Alberts, J. K. (2007). Burned by bullying in the American workplace: Prevalence, perception, degree and impact. Journal of Management Studies, 44(6), 837-862. authoritative version of the article. Please do not copy or cite without authors' permission. The final article will be available, upon publication, via its DOI: 10.1037/ocp0000137 
Luthans, F., Youssef, C. M., \& Avolio, B. J. (2007). Psychological Capital: Developing the Human Competitive Edge (p. 3). Oxford: Oxford University Press.

Maslach, C., Schaufeli, W. B., \& Leiter, M. P. (2001). Job burnout. Annual Review of Psychology, 52(1), 397-422.

Maslach, C., \& Jackson, S. E. (1986). MBI: Maslach Burnout Inventory. Manual Research Edition. Palo Alto: University of California.

Namie, G., \& Lutgen-Sandvik, P. E. (2010). Active and passive accomplices: The communal character of workplace bullying. International Journal of communication, 4, 31 .

Newman, D.A. (2003). Longitudinal modeling with randomly and systematically missing data: A simulation of ad hoc, maximum likelihood, and multiple imputation techniques. Organizational Research Methods, 6, 328-362.

Nielsen, M. B., \& Einarsen, S. (2013). Can observations of workplace bullying really make you depressed? A response to Emdad et al. International Archives of Occupational and Environmental Health, 86 (6), 717-721.

Nielsen, M. B., \& Einarsen, S. (2018). What we know, what we do not know, and what we should and could have known about workplace bullying: An overview of the literature and agenda for future research. Aggression and Violent Behavior, 42, 71-83.

Nielsen, M. B., Hoel, H., Zapf, D., \& Einarsen, S. (2015). Exposure to aggression in the workplace. In S. Clarke, T.M. Probst, F. Guldenmund, \& J. Passmore (Eds.), The Wiley Blackwell Handbook of the Psychology of Occupational Safety and Workplace Health (205227). Chichester: Wiley Blackwell.

O'Hara, R. (1999). Occupational health and musculoskeletal pain at work: an investigation of individual and organisational factors. University of Sheffield, UK: Unpublished $\mathrm{PhD}$ thesis. authoritative version of the article. Please do not copy or cite without authors' permission. The final article will be available, upon publication, via its DOI: 10.1037/ocp0000137 
Ortega, A., Høgh, A., Pejtersen, J. H., \& Olsen, O. (2009). Prevalence of workplace bullying and risk groups: a representative population study. International Archives of Occupational and Environmental Health, 82(3), 417-426.

Plopa, M., Plopa, W., \& Skuzińska, A. (2017). Bullying at work, personality and subjective well-being. Journal of Occupational Health Psychology, 22(1), 19.

Rayner, C., Hoel, H., \& Cooper, C. L. (2002). Bullying at work: What we know, who is to blame and what can we do. London: Taylor Francis.

Rhoades, L., \& Eisenberger, R. (2002). Perceived organizational support: a review of the literature. Journal of Applied Psychology, 87(4), 698-714.

Schneider, S. L. (2001). In search of realistic optimism: Meaning, knowledge, and warm fuzziness. American Psychologist, 56(3), 250.

Seligman, M. (2011). What you can change... and what you can't. Nicholas Brealey Publishing.

Shieh, G. (2009). Detecting interaction effects in moderated multiple regression with continuous variables power and sample size considerations. Organizational Research Methods, 12(3), 510-528.

Stride, C., Wall, T. D., \& Catley, N. (2008). Measures of job satisfaction, organisational commitment, mental health and job related well-being: a benchmarking manual. John Wiley \& Sons.

Totterdell, P., Hershcovis, M. S., Niven, K., Reich, T. C., \& Stride, C. (2012). Can employees be emotionally drained by witnessing unpleasant interactions between coworkers? A diary study of induced emotion regulation. Work \& Stress, 26(2), 112-129. authoritative version of the article. Please do not copy or cite without authors' permission. The final article will be available, upon publication, via its DOI: 10.1037/ocp0000137 
Vartia, M. A. (2001). Consequences of workplace bullying with respect to the well-being of its targets and the observers of bullying. Scandinavian Journal of Work, Environment \& Health, 63-69.

Verkuil, B., Atasayi, S., \& Molendijk, M. L. (2015). Workplace bullying and mental health: a meta-analysis on cross-sectional and longitudinal data. PloS One, 10(8), e0135225.

Warr, P. (1990). The measurement of wellbeing and other aspects of mental health. Journal of Occupational and Organizational Psychology, 63(3), 193-210. authoritative version of the article. Please do not copy or cite without authors' permission. The final article will be available, upon publication, via its DOI: 10.1037/ocp0000137 
Table 1: Means, standard deviations and intercorrelations of all study variables

\begin{tabular}{|c|c|c|c|c|c|c|c|c|c|c|c|c|c|c|c|}
\hline & \multirow[t]{2}{*}{ Mean } & \multirow[t]{2}{*}{ SD } & \multicolumn{13}{|c|}{ Correlations } \\
\hline & & & 1 & 2 & 3 & 4 & 5 & 6 & 7 & 8 & 9 & 10 & 11 & 12 & 13 \\
\hline 1. Age $-\mathrm{t} 1$ & 43.4 & 9.37 & & & & & & & & & & & & & \\
\hline 2. Organizational tenure $-\mathrm{t} 1$ & 13.6 & 9.82 & $.60 * *$ & & & & & & & & & & & & \\
\hline 3. Gender ${ }^{\mathrm{a}}-\mathrm{t} 1$ & 1.41 & .49 & .13 & $.15^{*}$ & & & & & & & & & & & \\
\hline 4. Experienced bullying $-\mathrm{t} 1$ & 1.62 & .61 & -.05 & .04 & .01 & & & & & & & & & & \\
\hline 5. Witnessed bullying $-\mathrm{t} 1$ & 2.06 & .83 & $-.18 *$ & -.05 & .06 & $.71 * *$ & & & & & & & & & \\
\hline 6. Optimism $-\mathrm{t} 1$ & 3.22 & .92 & .11 & -.02 & -.12 & $-.33 * *$ & $-.28 * *$ & & & & & & & & \\
\hline 7. Supportive supervisory style $-\mathrm{t} 1$ & 3.41 & 1.20 & .08 & -.10 & -.05 & $-.50 * *$ & $-.35 * *$ & $.29 * *$ & & & & & & & \\
\hline 8. Co-worker support - $\mathrm{t} 1$ & 3.54 & .96 & .04 & -.09 & -.05 & $-.43 * *$ & $-.24 * *$ & $.45^{* *}$ & $.48 * *$ & & & & & & \\
\hline 9. Anxiety $-\mathrm{t} 1$ & 2.67 & 1.04 & -.02 & .05 & -.03 & $.57 * *$ & $.47 * *$ & $-.36 * *$ & $-.46 * *$ & $-.44 * *$ & & & & & \\
\hline 10. Depression $-\mathrm{t} 1$ & 2.33 & 1.19 & -.05 & .09 & .07 & $.56 * *$ & $.45^{* *}$ & $-.48 * *$ & $-.53 * *$ & $-.52 * *$ & $.84 * *$ & & & & \\
\hline 11. Emotional Exhaustion - $\mathrm{t} 1$ & 3.50 & 1.78 & .02 & .08 & .06 & $.57 * *$ & $.48 * *$ & $-.47 * *$ & $-.45 * *$ & $-.46 * *$ & $.77 * *$ & $.80 * *$ & & & \\
\hline 12. Anxiety - t2 & 2.67 & 1.11 & .08 & .11 & -.05 & $.61 * *$ & $.50 * *$ & $-.31 * *$ & $-.40 * *$ & $-.40 * *$ & $.70 * *$ & $.59 * *$ & $.55^{* *}$ & & \\
\hline 13. Depression - t2 & 2.31 & 1.17 & .06 & $.18^{*}$ & -.01 & $.56 * *$ & $.43 * *$ & $-.42 * *$ & $-.45 * *$ & $-.52 * *$ & $.59 * *$ & $.65 * *$ & $.56^{* *}$ & $.80 * *$ & \\
\hline 14. Emotional Exhaustion - $\mathrm{t} 2$ & 3.51 & 1.92 & .01 & .09 & .03 & $.49 * *$ & $.46^{* *}$ & $-.34 * *$ & $-.38 * *$ & $-.38 * *$ & $.60 * *$ & $.64 * *$ & $.66^{* *}$ & $.74 * *$ & $.77 * *$ \\
\hline
\end{tabular}

Notes

a 1 = Female, 2 = Male

$*$ indicates correlation is significant at the $\mathrm{p}<.05$ level, $* *$ indicated correlation is significant at the .01 level 
Table 2: Results of regressing outcomes on witnessed bullying

\begin{tabular}{lccc}
\hline & \multicolumn{3}{c}{ Time 2 outcomes } \\
& Emotional exhaustion & Depression & Anxiety \\
\hline Age & -.04 & .01 & .09 \\
Organizational tenure & .08 & .11 & -.01 \\
Gender & -.02 & .04 & .03 \\
Experienced bullying & .09 & $.23^{*}$ & $.26^{* *}$ \\
Emotional exhaustion - $\mathrm{t} 1$ & $.51^{* * *}$ & & \\
Depression - $\mathrm{t} 1$ & & $.49^{* * *}$ & \\
Anxiety - $\mathrm{t} 1$ & & & $.51^{* * *}$ \\
Witnessed bullying & .13 & .04 & .06 \\
\hline $\mathrm{R}^{2}$ & .43 & .48 & .53 \\
\hline
\end{tabular}

Figures in main section of table are standardized regression (beta) coefficients

$* \mathrm{p}<.05 ; * * \mathrm{p}<.01 ; * * * \mathrm{p}<.001$ 
Table 3: Results of witnessing moderation analyses

\begin{tabular}{|c|c|c|c|c|c|c|c|c|c|}
\hline \multirow[b]{2}{*}{ Age $-\mathrm{t} 1$} & \multicolumn{3}{|c|}{ Emotional Exhaustion } & \multicolumn{3}{|c|}{ Depression } & \multicolumn{3}{|c|}{ Anxiety } \\
\hline & -.01 & -.03 & -.03 & .05 & .04 & .04 & .12 & .11 & .12 \\
\hline Organizational tenure $-\mathrm{t} 1$ & .07 & .07 & .08 & .09 & .09 & .09 & -.03 & -.03 & -.03 \\
\hline Gender $-\mathrm{t} 1$ & .01 & -.01 & -.01 & .09 & .07 & .05 & .06 & .05 & .08 \\
\hline Experienced bullying $-\mathrm{t} 1$ & .08 & .08 & .03 & $.21 *$ & $.19^{*}$ & .14 & $.24 * *$ & $.23 * *$ & $.22 *$ \\
\hline Emotional exhaustion - $\mathrm{t} 1$ & $.51 * * *$ & $.52 * * *$ & $.53 * * *$ & & & & & & \\
\hline Depression - $\mathrm{t} 1$ & & & & $.45 * * *$ & $.49 * * *$ & $.42 * * *$ & & & \\
\hline Anxiety - t1 & & & & & & & $.50 * * *$ & $.53 * * *$ & $.54 * * *$ \\
\hline Witnessed bullying $-\mathrm{t} 1$ & .10 & .11 & .11 & .01 & -.03 & .05 & .03 & .00 & .05 \\
\hline Optimism $-\mathrm{t} 1$ & -.01 & & & -.08 & & & -.03 & & \\
\hline Supportive supervisory style $-\mathrm{t} 1$ & & .01 & & & -.03 & & & .01 & \\
\hline Co-worker support $-\mathrm{t} 1$ & & & -.01 & & & $-.19 * *$ & & & -.05 \\
\hline Interaction (optimism) & -.12 & & & $-.15^{*}$ & & & $-.12 *$ & & \\
\hline Interaction (supervisor $\mathrm{S}$ ) & & -.07 & & & $-.19 * *$ & & & $-.15^{*}$ & \\
\hline Interaction (co-worker S) & & & $-.15^{*}$ & & & $-.13 *$ & & & -.11 \\
\hline $\mathrm{R}^{2}$ & .44 & .44 & .44 & .50 & .51 & .51 & .54 & .55 & .54 \\
\hline
\end{tabular}

Figures in main section of table are standardized regression (beta) coefficients

$* \mathrm{p}<.05 ; * * \mathrm{p}<.01 ; * * * \mathrm{p}<.001$ 
Figure 1: Moderating effect of optimism on the relationship between witnessing bullying and depression

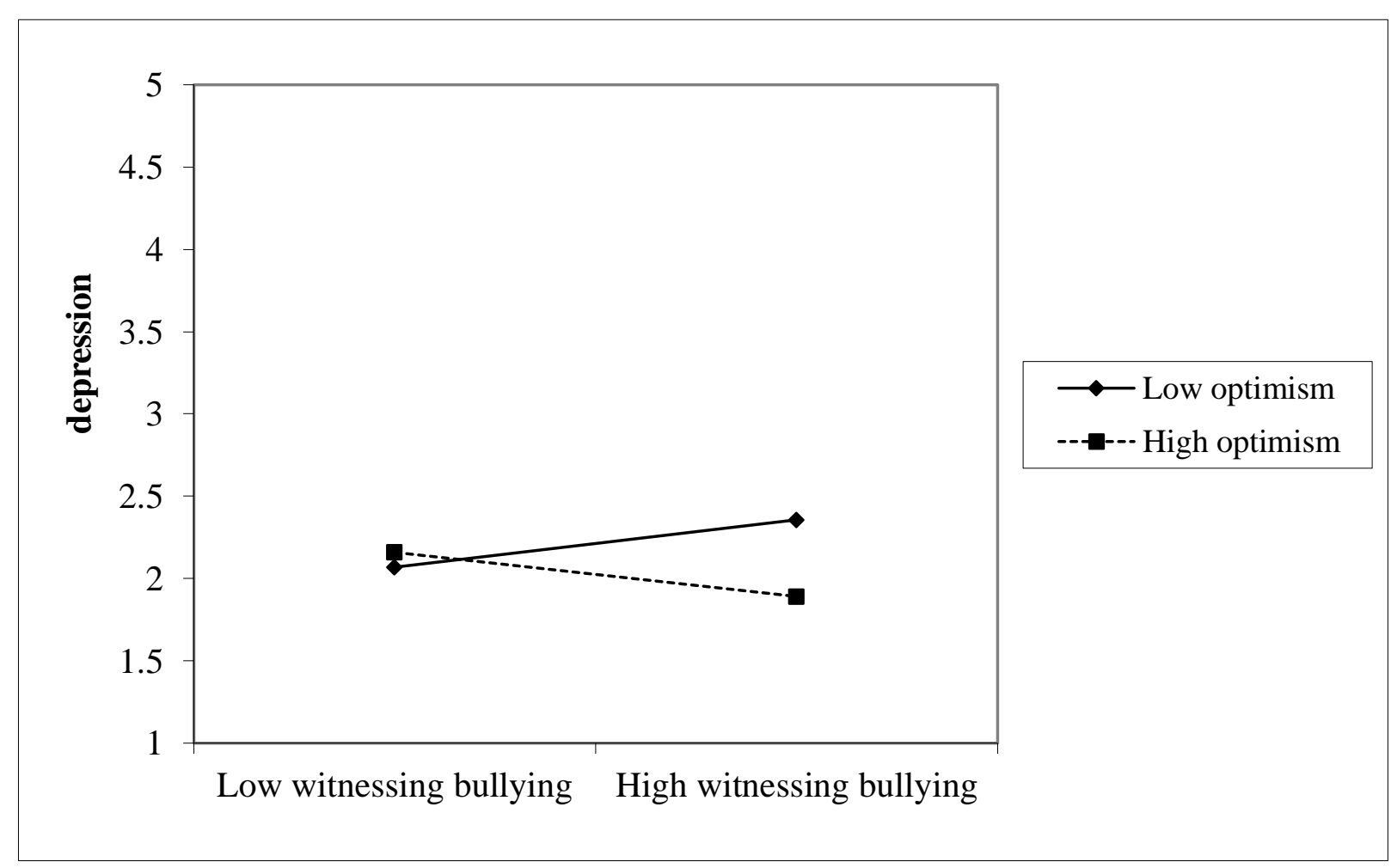

36

(c) 2018, American Psychological Association. This paper is not the copy of record and may not exactly replicate the final, authoritative version of the article. Please do not copy or cite without authors' permission. The final article will be available, upon publication, via its DOI: 10.1037/ocp0000137 
Figure 2: Moderating effect of co-worker social support on the relationship between witnessing bullying and emotional exhaustion

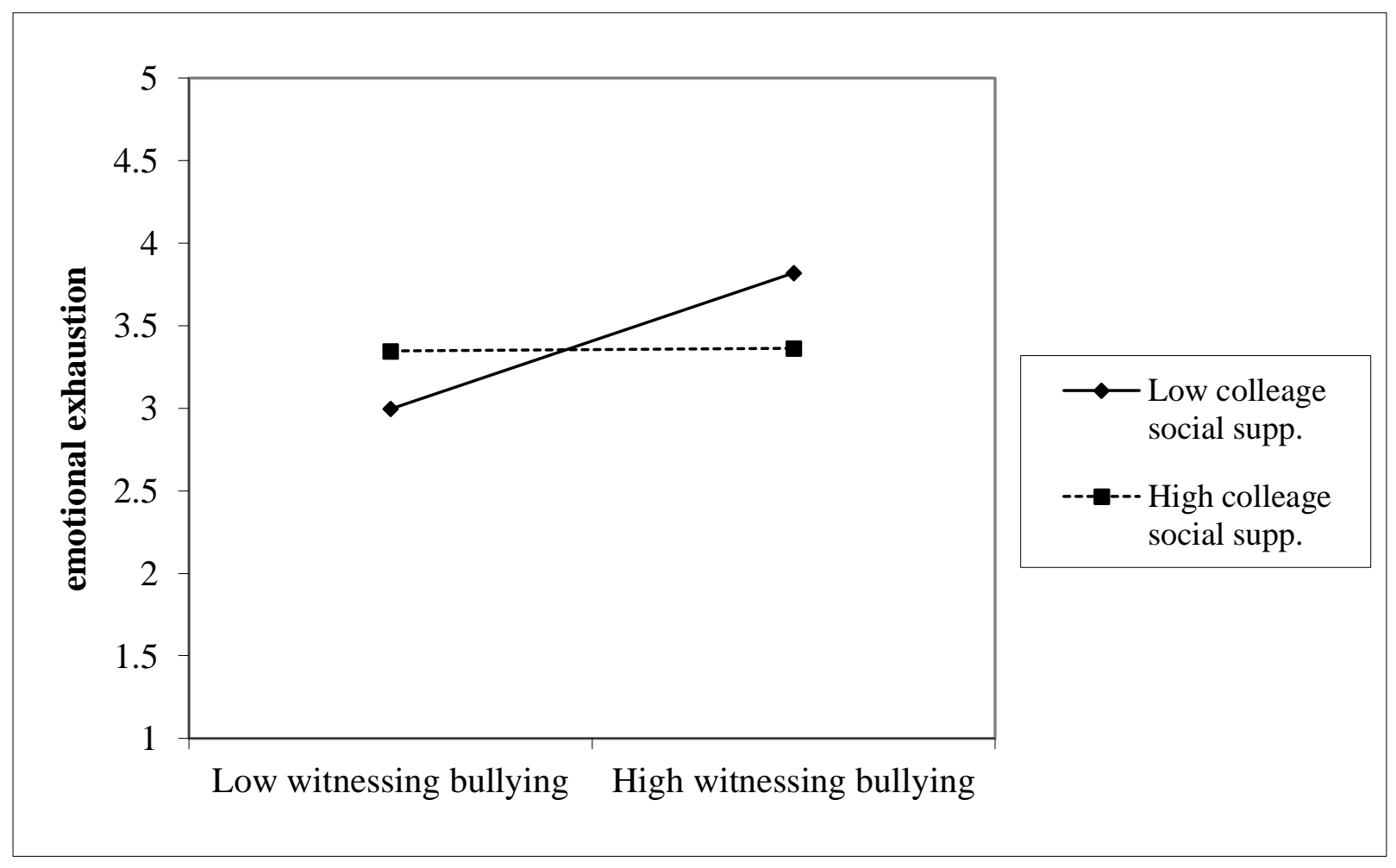


Figure 3: Moderating effect of supportive supervisory style on the relationship between witnessing bullying and anxiety

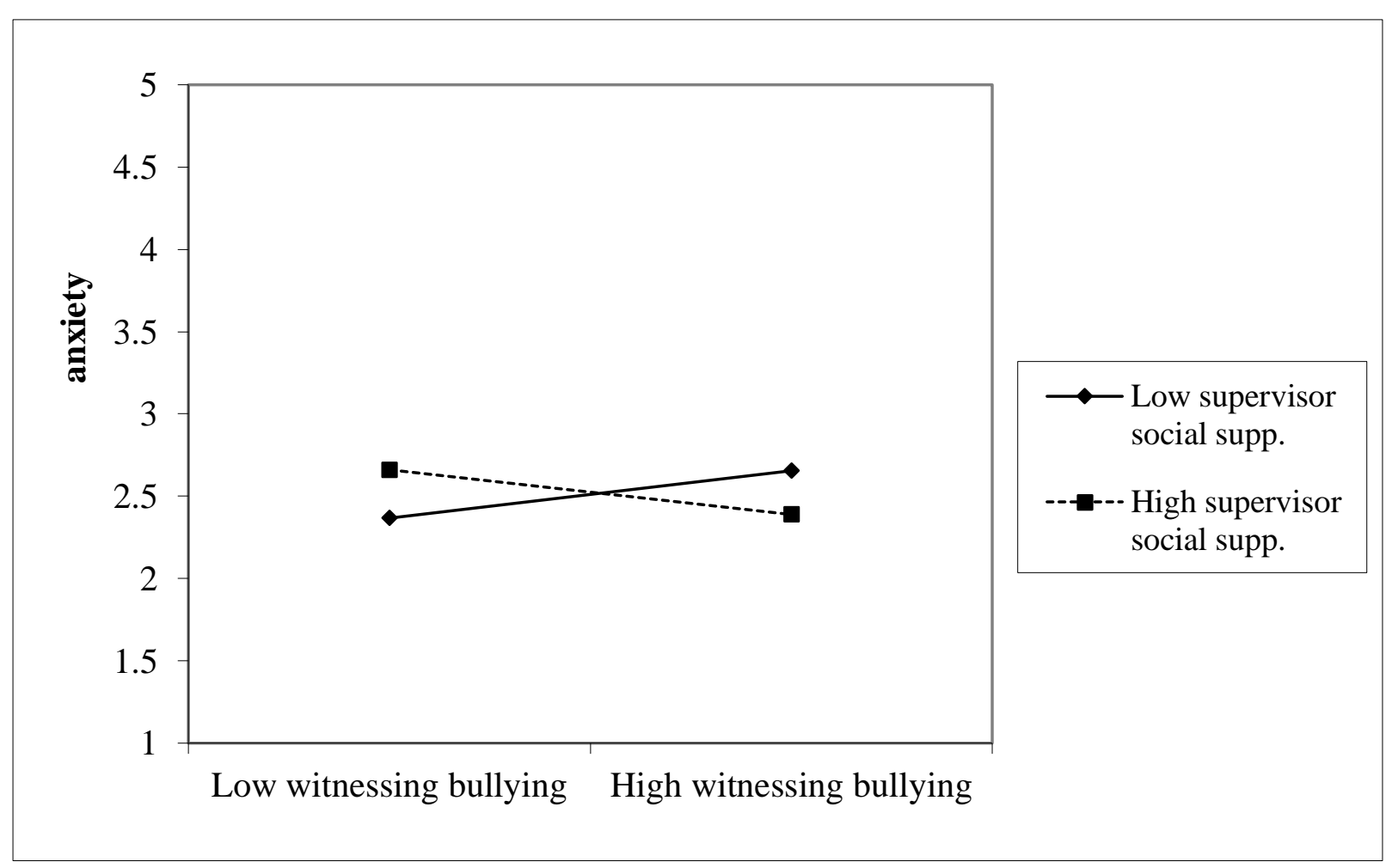

38

(c) 2018, American Psychological Association. This paper is not the copy of record and may not exactly replicate the final, authoritative version of the article. Please do not copy or cite without authors' permission. The final article will be available, upon publication, via its DOI: 10.1037/ocp0000137 


\section{Appendix}

\section{Witnessing Bullying Items}

How often have you witnessed information being withheld that affects people's performance?

How often have you witnessed insulting remarks being made about people, their attitudes or their private lives?

How often have you witnessed intimidating behaviour?

How often have you witnessed opinions and views being ignored?

How often have you witnessed someone being exposed to an unmanageable workload?

How often have you witnessed someone being shouted at or being the target of spontaneous anger? 